\title{
The Johannesburg negotiated bus rapid transit contract: How has it benefitted the stakeholders?
}

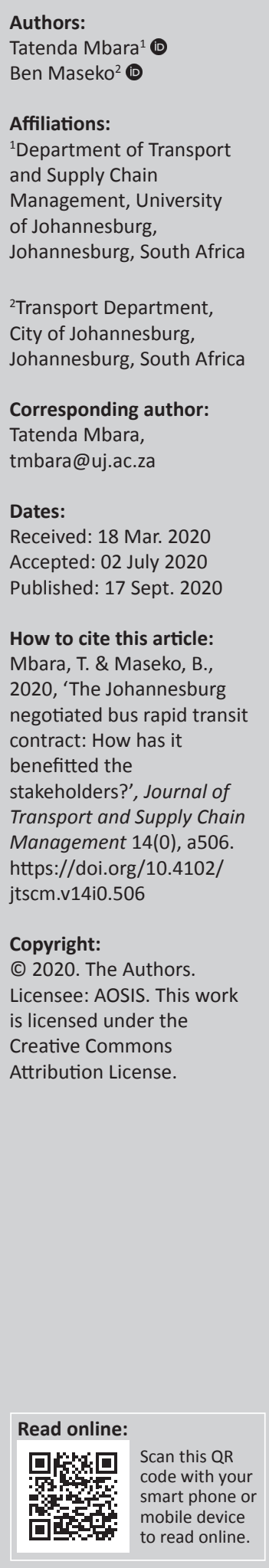

Background: In 2009 and 2013, the Transport Department, City of Johannesburg, negotiated with taxi operators and introduced the bus rapid transit (BRT) initiative on two routes. The protracted negotiations culminated into the displacement of approximately 900 minibuses on the two routes replaced by the BRT system. The mechanism used was to negotiate with the minibus taxi operators and compensate them for surrendering their vehicles that gave way for the BRT buses.

Objectives: The objective of this article is to ascertain how the City of Johannesburg, taxi operators and drivers benefitted from the implementation of the BRT system.

Method: A mixed-methods research paradigm was used. Quantitative data were collected from operators and drivers on how their skills and welfare have changed as a result of the implementation of the BRT initiative. Unstructured questionnaires were used to obtain qualitative data from the Transport Department, City of Johannesburg, and from nine taxi associations' representatives.

Results: The results revealed that there were considerable benefits that accrued to the former taxi operators as well as drivers. Former minibus taxi operators and drivers' welfare have improved. They have also gained knowledge and skills in operating the formal public transport system. The benefits were, however, at the expense of the City of Johannesburg.

Conclusion: Notwithstanding taxi operators' reservations, their participation was beneficial. The study focused solely on the benefits to the key stakeholders of the negotiated contract without addressing costs that have contributed to those benefits. Future research needs to undertake a comprehensive study that addresses both costs and benefits to determine whether these benefits are not at the expense of exorbitant costs.

Keywords: bus rapid transit; negotiated contract; stakeholders; service excellence; knowledge and skills; welfare; environment; management.

\section{Introduction}

In many developing countries, urban public transport is characterised by the use of low-capacity vehicles (minibuses and sedan motor cars) and cut-throat competition. This has contributed to severe traffic congestion. The unprecedented congestion that is a common phenomenon in larger cities, compounded with the growth of population, has ignited fresh thinking on the role of the informal sector's contribution in meeting the demand for public transport (Mbara, Dumba \& Mukwashi 2014). Of importance is to ask how these countries are going to revive their formal public transport systems? The development of formal public transport systems is a key element in providing a sustainable urban transport structure.

Authorities in many sub-Saharan cities are endorsing large-capacity public transport systems as the appropriate solution to address public transport challenges. Nigeria was the first country to introduce the bus rapid transit (BRT) transport system in the capital city of Lagos in 2008. Tanzania opened its BRT system in Dar es Salaam in May 2016 and thus became the first East African country to operate BRT. According to the Global Labour Institute (GLI) (2019) and also mentioned by Verachtert et al. (2015), the cities of Nairobi in Kenya and Kampala in Uganda intend to introduce BRT. In South Africa, BRTs have been introduced in Johannesburg, Cape Town and Tshwane and are in various implementation stages in at least four other cities. 
From the foregoing discussion, it is clear that African cities have either introduced larger capacity public transport systems or intend to implement it in an endeavour to address their urban public passenger transport challenges. In the City of Johannesburg (the subject of this article), BRT was introduced on two routes in 2009 and 2013, through negotiated contracts between the City of Johannesburg (hereafter referred to as 'the City') and minibus taxi operators.

The City took a bold decision in partnering with the taxi industry, whose operations are regarded as informal. The choice of a negotiated contract was dictated by the operating environment, as attempts to introduce any new form of public transport that directly challenges the taxi industry were bound to create violence and expected to be resisted by minibus operators. The success of BRT was built on the incorporation of taxi operators whose vehicles were plying the proposed BRT routes. A negotiated contract was the most ideal, as an open tender would have brought other players and not necessarily taxi operators.

While many studies on BRT, such as Kulyk and Hardy (2003), Maunganidze (2011) and Oviedo et al.(2019), have focused on passenger benefits, this article mainly focuses on the benefits realised by the parties bound by the negotiated contract. The two parties to the agreement were the City and taxi operators. In addition, albeit not a party to the agreement, there were also minibus drivers who were retrained to drive BRT buses. The question that arises is how the stakeholders have benefitted from this partnership? This article examines the perceived benefits that have been acquired by the various parties following the introduction of BRT in the City.

The next section explores the literature with specific focus on methods of procuring public transport services and an overview of institutional and management structures of BRTs. The remainder of the article is arranged as follows: section 'Methodology' summarises the study methodology, section 'Results' covers the findings, section 'Factor analysis' explain correlations by reducing a large number of variables, section 'Discussion' discusses issues emanating from the article and finally section 'Conclusion' draws the main conclusions from the study.

\section{Literature review}

\section{Public transport procurement methods}

Increasingly, the tendering of bus services is a strategy that some countries, mainly in the developed world, have instituted to address the challenges of urban public transport (Hidson \& Müller 2003). Tendering entails the procurement of bus services by an authority, either the government or local authority. According to Kavanagh (2016), the method used for the procurement of services is determined by factors such as the type of goods or services being procured, the nature and sophistication of the market for the goods or services and the will of those making the procurement decisions.
There are different forms of contracting bus services. The most common one is a competitive tendering system (Filippini, Koller \& Masiero 2015). In essence, competitive tendering allows a successful tenderer the exclusive right to deliver a service in accordance with predetermined conditions. Van de Velde (2003) observed that tendering of gross cost contracts was the most common way of competitive tendering in Europe. The gross cost option requires the authority (Government or Municipal) to determine the routes to be operated and the fares charged. The fare revenue accrues to the authority, which then pays the private an agreed-upon amount per kilometre travelled (Windecker 2002). While the gross cost contract gives maximum control to the authorities, it requires close supervision to ensure that the operators are running their routes as scheduled. In addition, the operator has no incentive to attract customers and ensure optimum revenue collection (The World Bank Group \& PPIAF 2006; Windecker 2002). Thus, the gross cost contract places greater demands on the authority, including initiating measures for service improvements. Armstrong-Wright (2000) pointed out that the concerns on gross cost contract compelled London Transport to shift from the gross cost model to the net cost model. The net cost model requires the authority to specify services but all the revenue accrues to the operator. This then gives the operator an incentive to collect revenue and operate the route efficiently. The net cost model also exposes the operator to demand risk and reduces the risk of open-ended subsidies.

Another method of procuring public transport services is through negotiation. According to the World Bank (2018:1), 'negotiation is a process through which each party tries to achieve their goals in the context of the relationship with the other party'. A negotiated contract is awarded on the basis of a direct agreement with the service provider, without going through the competitive bidding process. Therefore, negotiation provides flexibility and permits the authority to realise the best value solution for a public body.

Clearly, the best value for money may not be the lowest cost. Demel et al. (2013:4) argued that negotiation provided 'a format for realising greater value to the agency through contractor concessions'. The World Bank (2018) identified the following reasons, inter alia, as adding additional value to the public sector or borrower who embarks on the negotiation path: terms and requirements can be varied, and a more effective and economically advantageous bid can be reached.

Hensher and Stanley (2003) reasoned that negotiated contractual agreements based on achieving designated performance objectives hold the best prospect of delivering better value for money in terms of meeting multiple objectives. Thus, a negotiated contract provides flexibility for the authority to select a service provider, it saves both time and costs, and the service provider can be expeditiously engaged. 
Notwithstanding the advantages of negotiated contracts discussed above, such contracts are also beset by shortcomings. A negotiated contract is less transparent and potentially more harmful to the principle of equal treatment and genuine competition (Batoev \& Schlosser 2013). The costs may become higher as they are likely to be driven by the lack of competitive bidding. A negotiated contract provides fewer options for the client to make a choice and there could be less innovation. Such a contract also requires more time for the negotiation process to take place.

In South Africa, there are statutory provisions for contracting authorities to enter into negotiated contracts for a maximum period of 12 years. According to the National Land Transport Act (2009:54), Section 5, subparagraph 41 (b), the main objectives of negotiated contracts are to:

- integrate services forming part of integrated public transport networks in terms of their integrated transport plans

- promote the economic empowerment of small business or of persons previously disadvantaged by unfair discrimination

- facilitate the restructuring of a parastatal or municipal transport operator to discourage monopolies.

Walters and Cloete (2008:7) noted that the introduction of negotiated contracts was originally conceptualised 'as a measure to provide a transitional arrangement for provincial and municipal-owned bus companies "to get fit" for the tendering system'. Thus, negotiated contracts were introduced as a deliberate measure to support provincialand municipal-owned bus companies whose fleet were old and unable to meet the minimum tender requirements age specification.

\section{Overview of institutional and management of bus rapid transit}

Flores and Diaz (2019) have undertaken extensive studies on BRT governance-related issues in six Latin American cities and this section mainly draws from their findings. The authors observed that 'project champions deliberately structure implementation to ensure that incumbent, private operators of bus services had the option of being included in the operation of the BRT systems' as happened in Buenos Aires, Mexico City and Quito (Flores \& Diaz 2019:5). The retention of incumbent companies would be achieved by crafting bid conditions that would favour incumbents. The authors also noted that private BRT operators grew overtime and inculcate professional management in the enterprise.

Hidalgo and Graftieaux (2008) argued that the success of BRT projects was strongly depended on key decision-makers. The clear visions that were put in place by the political leadership in the cities of Curitiba, Bogota and Jarkata are cases in point. In addition, the creation of an adequate regulatory framework is a critical requirement in addressing technical details. The 11 cities studied by
Hidalgo and Graftieaux (2008:82) in Latin America and Asia 'required changes in their regulations or in the definition of authority or created new institutions to develop the projects'. In the case of Lagos, the establishment of the Lagos Area Metropolitan Transport Authority (LAMATA) under the Lagos State Ministry of Transport was a critical step for the BRT project (Klopp, Harber \& Quarshie 2019).

In Quito, Eduador, the government of the municipality of Quito operates the BRT system, which integrates the city's public transportation system. From 2014, revenues were managed under a common system where operators of each company are paid according to kilometres travelled and passengers transported (Flores \& Diaz 2019). In Buenos Aires, the separation of institutional urban transportation roles in the field of urban transportation limits the responsibilities of the city government to road administration, while the design, management and control of the operation of the different bus services are the responsibility of national government (Flores \& Diaz 2019).

Flores and Diaz (2019) observed that in Santiago, Chile, Central Government was responsible for the planning and management of the BRT system through the Metropolitan Public Transportation Board (DTPM), under the Ministry of Transportation and Telecommunications (MTT), while the management of financial resources that included administration, accounting, remuneration and custody of resources was decentralised. The DTPM has an Executive Secretariat headed by the Metropolitan Transportation Director, appointed by the President of the Republic, a Technical Secretariat in charge of the overall planning of the system and an Advisory Board made up of civil society representative that advises both Secretariats (Flores \& Diaz 2019). The roles of the Board are:

to propose the strategic guidelines that direct the implementation of the Urban Transportation Plan of the city of Santiago, and to coordinate the efforts of both public and private actors involved in the work of infrastructure provisioning, operation of the different modes, financing, and supplying of complementary services.(p. 29)

Institute for Transportation and Development Policy (ITDP) (n.d.) observed that in cities like Curitiba and Sao Paulo, fare collection was managed directly by the transit authority, and in other Brazilian cities, private transit operators had ceded control over fare collection to public authorities. This can be contrasted with the developed countries where fare collection is handled by the same company that operates the vehicles (Flores \& Diaz 2019).

\section{Study area}

In South Africa, the City of Johannesburg (the commercial hub of the country) started to plan the BRT initiative in 2006. The main offerings of BRT, popularly known as Rea Vaya (a colloquial term meaning 'we are going'), were to reduce traffic congestion and to provide an alternative form of public transport that is safe, reliable and affordable in the city. The project was given impetus by the successful bid to 
host the 2010 FIFA Soccer World Cup, the first ever to be held on the African continent. According to Allen (2013), the following were the objectives of BRT: economic growth, poverty alleviation, sustainable development, restructuring the apartheid city and good governance.

At the planning stage, it became evident that the implementation of BRT was bound to be resisted by the minibus operators who were benefitting from the prevailing system, and hence, they had to be taken on board. As Venter (2016) pointed out, in some countries in Africa and Latin America, improving public transport entails dealing with incumbent private sector operators providing informal paratransit services. The city was compelled to enter into a negotiated contract with taxi operators. As mentioned earlier, negotiated contracts are provided for in South Africa's legislation. Therefore, the negotiations with the taxi operators boded well with the legislative goals to increase the participation of marginalised groups to operate formal public transport.

Negotiations with the minibus operators affected by future bus operations commenced in 2006 as Phase 1A. From the taxi operators' side, there were divergent views on BRT. There were those minibus taxi operators who opposed BRT because they were concerned that the system would take over their businesses and leave them with no income to support their families. On the other hand, there were some business-minded taxi operators who saw a business opportunity with the introduction of the BRT system in the city. Taxi operators who were in favour of BRT were intimidated, vehicles were burnt and lives were lost.

The negotiations culminated into an agreement that created a new BRT operating company known as Piotrans (Pty) Ltd for Phase 1A which started operations in August 2009. The deal resulted in the displacement of 585 minibus vehicles and enabled 313 minibus taxi owners, drawn from nine taxi associations to become stakeholders in the BRT corporate bus operations.

Phase 1B was implemented in October 2013. This phase resulted in the removal of 312 vehicles owed by 174 minibus taxi operators. In this phase, an already existing bus company, Public Utility Transport Corporation (PUTCO), which was also operating on the route, became a shareholder in a new company called Litsamaiso (Pty) Ltd. In both phases, the contract provided for penalties in the event that the company fails to meet the requirements, which include missing trips and unclean buses inter alia.

Negotiations and compensation were the mechanisms used in both phases to enable participation of the minibus taxi operators. The city would negotiate with the minibus taxi operators, and thereafter, the city would pay for their participation and for the surrendering of vehicles
TABLE 1: Summary of salient features of Phase $1 \mathrm{~A}$ and Phase $1 \mathrm{~B}$.

\begin{tabular}{|c|c|}
\hline Phase 1A & Phase 1B \\
\hline $\begin{array}{l}\text { - Nine taxi associations } \\
\text { - Tumber of taxis removed: } 585 \\
\text { - The operators involved: } 313 \\
\text { representatives from the taxi industry } \\
\text { - The City paid compensation of } \\
\text { R6600.00 per vehicle per month for } 4 \\
\text { years as from } 2009 \text {, and the operating } \\
\text { company Piotrans continue to pay } \\
\text { (6\% increase annually) } \\
\text { - Fee per kilometre is paid by the city } \\
\text { - Buses were bought by the company, } \\
\text { and the City used as a guarantor } \\
\text { - Fully assembled buses were bought } \\
\text { from abroad }\end{array}$ & $\begin{array}{l}\text { - Ten taxi associations } \\
\text { - Number of taxis removed: } 312 \\
\text { - Taxi operators involved: } 174 \\
\text { individuals, three from the taxi } \\
\text { industry and } 1 \text { from } \\
\text { - PUTCO } \\
\text { - An upfront amount of R870 } 000 \text { paid } \\
\text { per vehicle with a quarterly dividend } \\
\text { paid per share by the operating } \\
\text { company Litsamaiso (Pty) Ltd. } \\
\text { ( } 6 \% \text { increase annually) } \\
\text { - Fee per kilometre is paid by the city } \\
\text { - Kits were brought from abroad and } \\
\text { buses were assembled in South Africa }\end{array}$ \\
\hline
\end{tabular}

Source: Constructed by authors from information provided by the City of Johannesburg PUTCO, Public Utility Transport Corporation.

to make way for the BRT system. There were slight variations in the contract provisions of the two phases, and Table 1 shows the noticeable features of each phase.

Seftel (2013) cited some pains and gains of this negotiated contract. A significant gain of the negotiated contract was the trust that was crafted between parties with different interests but a common objective. The payment of a restraint of trade to shareholders by the city on a monthly basis that is not linked to the performance of the company is a serious disadvantage.

\section{Methodology}

A mixed-methods research design was used. Quantitative data were collected from taxi operators and drivers in regard to changes that have occurred as a result of the implementation of BRT through a negotiated contract. For the quantitative interviews, the target was to interview a third of drivers as well as a third of former taxi operators who are now shareholders in the two companies. Ultimately, 90 former taxi operators (approximately $50 \%$ of former taxi operators) and 56 drivers (approximately 30\% of drivers) from Phase 1B were interviewed. It is instructive to point out that BRT drivers were former taxi drivers. They were retrained to drive BRT buses.

Because of internal challenges and squabbles from the company's side, it was not possible to administer quantitative interviews for Phase 1A and data were collected for Phase $1 \mathrm{~B}$ only. In addition, unstructured questionnaires were used to obtain qualitative data from the city and three board members (former taxi operators) of Phase 1B. Ten city employees from the Transport Department serving in senior management positions were interviewed. These 10 employees were working in the following divisions: engineering and infrastructure, marketing, operations, planning and transformation.

A five-point Likert-type scale was used as a questioning technique. This technique was preferred as it is well suited to measure perception, attitude, values or behaviour (Wilson 2014) and can easily convert qualitative responses into quantitative values, and measures the level of agreement or disagreement (Davis 2014). 
The assessment of benefits focused on six factors:

- Knowledge and skills: Whether the new formal operational arrangement has imparted knowledge and skills to drivers and former taxi operators?

- Welfare: Whether the welfare of drivers and former taxi operators have positively changed?

- Service quality: Service-related aspects and benefits thereof.

- Environment: Whether the introduction of BRT has contributed to a better urban environment?

- Management: What is the role of shareholders (former minibus taxi operators) and how well is the company being managed?

- Economy: Has the introduction of BRT positively contributed to the economy of the City?

Bus rapid transit drivers (former taxi drivers) were interviewed on the first three factors, while former taxi operators were required to respond to all the factors, with the exception of the economy. The economy factor was confined to the city officials. The qualitative interviews covered all six aspects. The quantitative results of drivers and former taxi operators' interviews were cross-checked with the findings from qualitative interviews of the city personnel and the three former taxi operators on the company board.

\section{Results}

\section{Demographic characteristics of respondents and participants}

Table 2 summarises the demographic details of respondents of drivers and former taxi operators.

As shown in Table 2, the majority of drivers (89\%) were male drivers. Fifty per cent of drivers had no matric with $38 \%$ having a matric. In respect to former taxi operators, $84 \%$ were male taxi operators. Nearly $50 \%$ of the operators had no matric, $35 \%$ with matric, $8 \%$ with certificate, $5 \%$ diploma and $3 \%$ a degree.

Participants from the city consisted of eight men and two women. Six of them had a postgraduate qualification, two with a degree and one each with a diploma and a certificate. They had an average of 11 years work experience. The participants were drawn from the all the sections under the department of transport comprising: directorate, marketing, operations, transformations, planning, infrastructure and engineering. The questions asked were the same with those asked to former taxi operators, with the main focus being on environment and economy.

\section{Driver and former taxi operators' benefits Introduction}

Driver benefits were assessed on three variables, namely knowledge and skills and welfare and quality of service. Former taxi operators were assessed on five variables, knowledge and skills, welfare, quality of service, environment and management. As earlier discussed, a five-point Likerttype scale was used as a questioning technique. After analysing the key measurement indicators of each variable, these were collapsed as shown in Figures 1 and 2, which illustrate the views of drivers and former taxi operators. The variable indicators have been analysed for factor analysis that is discussed later.

\section{Knowledge and skills}

The results show that drivers have positively gained (approximately $90 \%$ agreed or strongly agreed) in knowledge and skills. The knowledge and skills indicators on which drivers benefited were in regard to driving skills, improved attitude towards customers, operational knowledge and positive business perceptions. Such results can easily be corroborated. As previously stated, BRT drivers were former taxi drivers. Taxi drivers are not subject to a code of conduct and no training is provided. As one former taxi operator remarked; 'Driving behaviour and attitude of taxi drivers leaves a lot to be desired'. (Male, former taxi operator, board member) Taxi drivers who were engaged to drive BRT buses were retrained. The training covered both practical and customer handling skills.

In respect of former taxi operators, the results depicted in Figure 2 indicate that they did not benefit much in terms of knowledge and skills acquisition. More than half of the former taxi operators disagreed or strongly disagreed in gaining knowledge and skills from the negotiated BRT project. The only indicator highlighted as beneficial pertained to training on managing formal public transport. However, the qualitative discussions conducted on three former taxi operators acknowledged the gain in knowledge

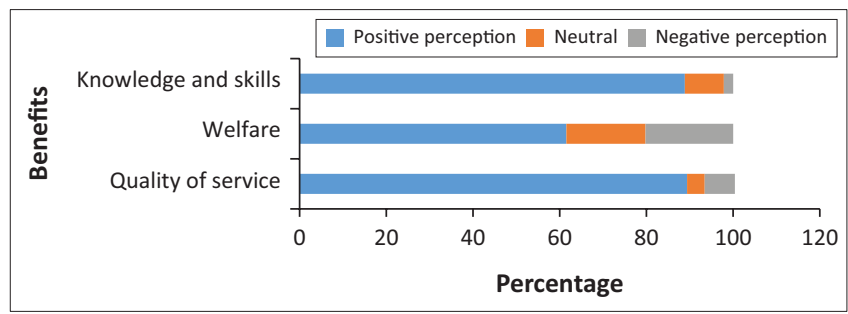

FIGURE 1: Driver views on benefits in regard to knowledge and skills, welfare and quality of service.

TABLE 2: Demographics details of respondents.

\begin{tabular}{|c|c|c|c|c|c|c|c|c|c|c|c|c|c|c|}
\hline \multirow[t]{3}{*}{ Variable } & \multicolumn{4}{|c|}{ Gender } & \multicolumn{10}{|c|}{ Educational qualifications } \\
\hline & \multicolumn{2}{|c|}{ Male } & \multicolumn{2}{|c|}{ Female } & \multicolumn{2}{|c|}{ No matric } & \multicolumn{2}{|c|}{ Matric } & \multicolumn{2}{|c|}{ Certificate } & \multicolumn{2}{|c|}{ Diploma } & \multicolumn{2}{|c|}{ Degree } \\
\hline & $n$ & $\%$ & $n$ & $\%$ & $n$ & $\%$ & $n$ & $\%$ & $n$ & $\%$ & $n$ & $\%$ & $n$ & $\%$ \\
\hline Drivers & 50 & 89 & 6 & 11 & 28 & 50 & 21 & 38 & 6 & 11 & 1 & 1 & - & - \\
\hline Former taxi operators & 76 & 84 & 14 & 16 & 44 & 49 & 31 & 35 & 7 & 8 & 5 & 5 & 3 & 3 \\
\hline
\end{tabular}




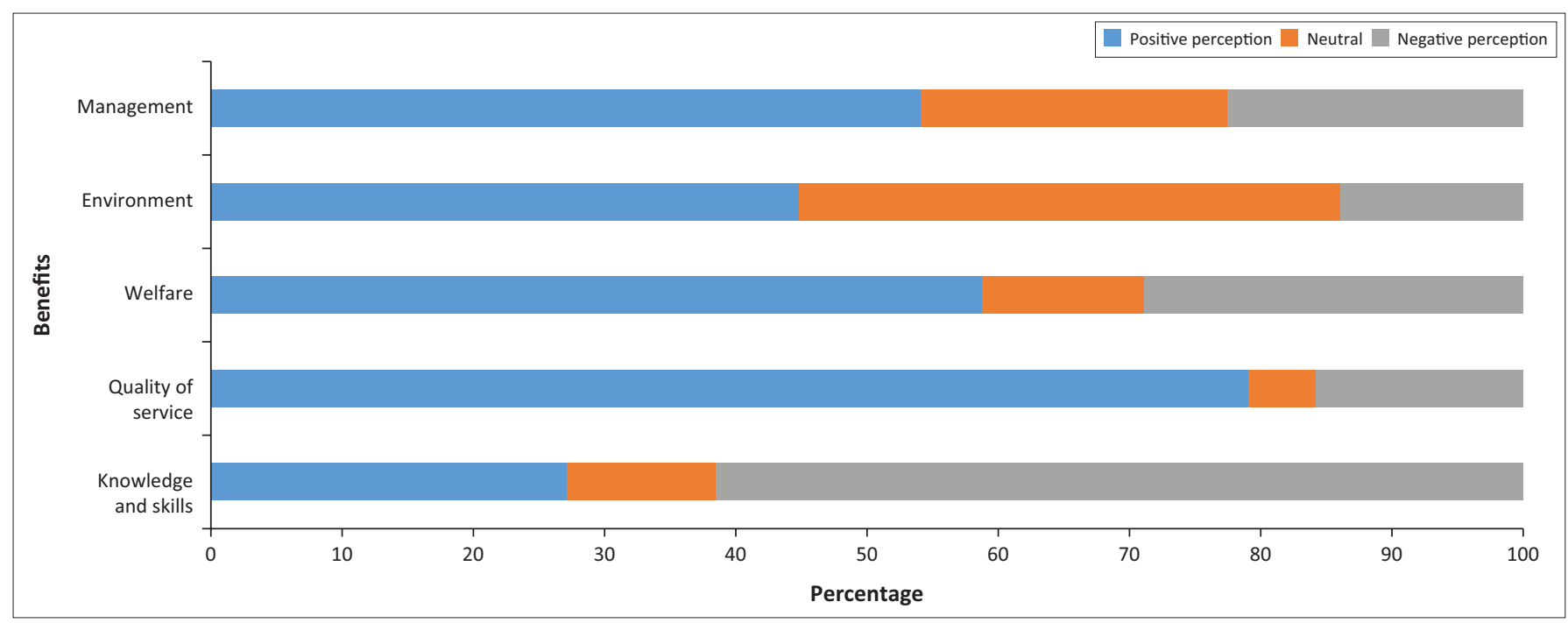

FIGURE 2: Former taxi operators' views on benefits in regard to knowledge and skills, welfare and quality of service, environment and management.

and skills following their engagement in BRT. One of the interviewees remarked:

'Good governance is something that I have learnt. In the past we had no rules to comply with when handling drivers. I have also learnt to look at my finances more carefully and I now appreciate what a financial statement entails.' (Male, Entrepreneur and Board member)

The other interviewee also stated: 'If I had to go back to operate taxis, the knowledge and skills I have gained will enable me to run the business successfully'. (Male, entrepreneur, Board Member) All the three interviewees who participated in the qualitative interviews were serving on the company board. Their positive responses may have been influenced by their involvement in the Board as they get training from time to time. The negativity was mainly expressed by former taxi operators who were shareholders but not sitting on the board. Their exclusion from being board members appears to have greatly influenced their negative perceptions.

The general consensus of participants from the City of Johannesburg was that the movement from informal to formal public transport accompanied by training and retraining had resulted in skills transfer for both the drivers and former taxi operators.

\section{Welfare}

Former taxi drivers indicated that they had benefitted from the change from being taxi drivers to BRT drivers (60\% agreed and strongly agreed). The indicators on which welfare benefits were gained include provision of medical aid and the general conditions of service obtaining at the new company. From the statistical analysis, these two aspects had a very high mean and a low standard deviation indicative of a close positive consensus. However, less than half of the driver respondents were of the view that they were being accorded the training that could enable them to be promoted and the human resources division was not supportive of their needs. The drivers also acknowledged that they were being paid more than before, they were working for less hours and the new operating regime had provided a pleasant working environment.

From the results depicted in Figure 2, former taxi operators, who are now shareholders in the new company, acknowledge that their welfare had improved as a result of their participation in the BRT-negotiated contract. The most notable benefits were: a reasonable financial compensation that was given, training that had contributed to an understanding of financial management and a hassle-free management regime that had replaced the cumbersome taxi management.

Participants in the qualitative surveys were in agreement that the welfare of drivers had significantly improved following the move from being a taxi driver to a BRT driver. A former taxi operator remarked that 'drivers were upskilled and unlike the long hours they used to work, they were now working for a fixed number of hours'. (Male, Board Member) An official from the City of Johannesburg pointed out that drivers were the major beneficiaries of the negotiated contract as they were now 'earning decent salaries and accessing medical aid, which was not the case with the previous employer'. (Female, Department of Transport)

The two aspects where more than half the respondents could not positively acknowledge the welfare benefits were in regard to the improvement of income as a result of participation in BRT and the effect of the restraint agreement not to allow tax operators to compete with BRT. The two issues are related. However, the results of qualitative interviews were different. The following remarks were given by three participants in the qualitative interview:

'I am in a better space. If anyone tells you that the restraint agreement has made taxi operators worse off, the person is telling a lie.' (Respondent 1, male, 55 years, Entrepreneur and Board member)

'Rea Vaya was the first meaningful black empowerment project as the other ones were catering for politicians only.' (Respondent 2, male, Entrepreneur, Board member) 
'Overall, the welfare of former taxi operators has improved. However, it also depended on individuals. As we were not used to get lump sums, others misused the money by undertaking unnecessary trips, divorcing and marrying other wives and the alike.' (Respondent 3, male, 50 years, Board member)

With the lump-sum payment, the common areas cited where taxi operators invested included housing, service stations and land acquisition. Such income generating ventures are evidence of wider benefits emanating from participation in the BRT project. The negativity shown by some former taxi operators in regard to non-improvement of income emanates from the fact that they were not directors sitting on the board. Ordinary board members perceive those sitting on the board as getting more money than themselves.

\section{Quality of service}

Although the service quality factor provides no direct benefits to drivers and former taxi operators, it was important to ascertain their views as the provision of reliable, affordable, safe and secure public passenger services was stated as key objectives for the city's decision to introduce BRT through a negotiated contract. Service quality was positively viewed by both drivers and former taxi operators. As evidenced in both Figures 1 and 2, driver respondents' were of the view that the BRT service was reliable, affordable, comfortable, safe, convenient and easily accessible by people with a disability. The drivers' views were shared by the former taxi operators (Figure 2). However, the issue concerning the operation of BRT with minimal competition gave diverse responses by both drivers and former taxi operators.

The service quality results augur well with the views expressed in the qualitative interviews. By and large, both the City of Johannesburg officials and the shareholders acknowledged that the quality of service was good, despite the failure to reach the expected patronage. In respect of the two flagged issues from the quantitative interviews concerning competition from other modes and speed, the qualitative interviews revealed that these two matters were related. The number of taxis that were surrendered was minimal, and therefore, BRT continues to compete with taxi services. The taxis also compete for road space and during the peak periods, and they encroach on the bus lane and in turn affecting the quality of service.

\section{Environment}

The results from Figure 2 indicate mixed views on the environmental benefits of BRT. A considerable number of respondents took a neutral position, indicative of the lack of knowledge on the effects of BRT on the environment. Clearly, environment appears to be a peripheral issue to taxi operators. Approximately $42 \%$ of respondents acknowledged that the BRT had contributed to a pleasant city environment. However, the results of the qualitative interviews revealed that the diesel Euro IV engine type which the buses use was less harmful and conducive to a cleaner urban environment. In regard to congestion and pollution, interviewees alluded to the reduction of traffic by citing the informal park and ride facilities that had developed on the BRT corridor. However, most participants from the city argued that meaningful environmental benefits can only be realised with the upscaling of BRT services to other corridors of the city. One participant from the city commented: 'congestion has not yet been addressed but with the growth of the BRT network, the system has potential to shift car users to public transport.' (Male, Transport Department) Some participants argued that the number of minibuses removed from the corridor was minimal to effect a reduction in congestion and pollution levels. Another participant from the city argued that the BRT stations and upgrades that had taken place around these stations have contributed to a congenial urban environment.

\section{Management}

Overall, respondents were positive in their level of participation, the appointment of board members, which is performed in a professional manner, and management of the company, which was within expectations of bus operating company agreement. The areas with high levels of negativity pertained to management issues, namely the appointment of management not being performed in a transparent manner, non-adherence to company policy by management and concern on how the company was being managed.

The three qualitative participants provided a positive consensus on management issues. The inclusion of $80 \%$ independents (people who were professionals and experienced) on the board and the impartation of management skills to former taxi operators on the board were cited as major benefits. The city was, however, of the view that the board should be completely independent. Although Phase $1 \mathrm{~A}$ is not part of this article, concerns were raised in having former taxi operators as the majority shareholders in the board as this has fuelled infighting among board members.

\section{The economy}

Concomitant with the initial objectives of the city in introducing BRT, the 10 participants from the city who were interviewed were requested to comment on the contribution of BRT to the following areas: employment, economic growth and sustainable development and good governance. There was a general consensus that BRT had positively impacted on employment. Participants cited employment that was generated during the construction phase, engagement of drivers, station staff and security personnel. Indirect downstream employment, for example, provision of uniforms by other companies, was also cited.

On economic growth, the city officials' views were that the BRT bus system had the potential to contribute to the growth of the economy. One participant remarked:

'There is no detailed study that has been undertaken on the impacts of BRT to the economy in Johannesburg, but the reduction in travel time should be translated to economic growth in the long term.' (Male, Department of Transport, City of Johannesburg) 
Other participants cited the enhanced accessibility of the poor that increases opportunities for jobs. The affordability of BRT in comparison to other public transport modes was also commented as a potential contributing factor to the growth of the economy. One participant mentioned: 'Rea Vaya is a cheaper mode of public transport and our assumption is that citizens are left with more disposable income which they can spend'.

As already alluded to in this article, the restructuring of the city post-apartheid was one of the priorities of the government and the city officials. Participants repeatedly referred to the transformation of the taxi industry, which empowered the previously marginalised taxi operators as a contributory factor to good governance. In addition, linking Soweto, a high-density area to the central business district (CBD) of Johannesburg, was considered to be a milestone.

\section{Factor analysis}

Indicators relating to the variable benefits of the BRT stakeholders (drivers and former taxi operators) were factors analysed using principal components analysis (PCA) with varimax rotation. In this study, factor analysis was performed as a construct validity technique. The suitability of data for factor analysis was assessed using the Kaiser-Meyer-Olkin (KMO) and the Bartlett's test of sphericity. The KMO analysis is undertaken to ascertain whether the sample size is adequate for factor analysis and should be at least 0.6 or above (Tabachnick \& Fidell 2013). The Bartlett test of sphericity checks whether there are adequate number of correlations between variables for factor analysis. Bartlett's test of sphericity should be significant $(p<0.05)$ for factor analysis to be considered appropriate.

\section{Drivers}

The PCA computed for drivers resulted in the following: The KMO value of 0.762 exceeding the recommended value of 0.6 and the Bartlett's test of sphericity reached statistical significance $(p<0.05)$, supporting the factorability of the data. Table 3 shows the results of factor analysis for drivers.

\section{Interpretation of driver factor analysis results}

The PCA analysis revealed the presence of three factors with eigenvalues greater than 1 explaining $69.65 \%$ of the total variance. Table 3 shows the three factors together with indicators that have been loaded on each factor. Indicators that failed to meet the criteria were discarded.

The indicators that load significantly to factor 1 (service excellence) are convenience, safety, affordability, reliability, ease of access, comfort and speed. In other words, for drivers, service excellence is explained by these seven indicators.
For factor 2, welfare can be explained by the following indicators: reduction in working hours, increased remuneration and improved conditions of service, congenial working environment and provision of medical aid.

The indicators embodied in Factor 3 (Knowledge and Skills) are increased employment options (brought by better training), improved operational knowledge, positive perception (formal compared to informal) and improved driving skills.

\section{Former taxi operators}

The PCA computed for former taxi operators resulted in the following: The KMO value of 0.766 exceeding the recommended value of 0.6 and the Bartlett's test of sphericity reached statistical significance $(p<0.05)$, supporting the factorability of the data.

\section{Interpretation of former taxi operators' factor analysis results}

The PCA analysis showed five factors with eigenvalues greater than one explaining $71.08 \%$ of the total variance. Table 4 shows the five factors together with indicators that have been loaded on each factor. The indicators demonstrate the benefits that explain each factor. The management factor is associated with transparency, adequate participation, capacitated management and professional appointment of the board. Indicators that explain service excellence are reliability and efficiency of the public transport system, ease access, improved speed, convenience and increased number of passengers. The third factor (environment) is associated with less pollution, pleasant environment, compliant of

TABLE 3: Results of factor analysis for drivers.

\begin{tabular}{|c|c|c|c|c|c|}
\hline Factor & Indicator & $\begin{array}{l}\text { Indicator } \\
\text { description }\end{array}$ & Loadings & Eigenvalues & Reliability \\
\hline \multirow{7}{*}{$\begin{array}{l}\text { Service } \\
\text { excellence }\end{array}$} & SE4 & Convenience & 0.922 & \multirow{7}{*}{5.293} & \multirow{7}{*}{0.819} \\
\hline & SE5 & Safety & 0.883 & & \\
\hline & SE1 & Affordability & 0.871 & & \\
\hline & SE3 & $\begin{array}{l}\text { Reliability and } \\
\text { efficient system }\end{array}$ & 0.843 & & \\
\hline & SE7 & $\begin{array}{l}\text { Easily accessed by } \\
\text { disabled }\end{array}$ & 0.821 & & \\
\hline & SE2 & Comfortable & 0.812 & & \\
\hline & SE6 & Speed & 0.771 & & \\
\hline \multirow[t]{5}{*}{ Welfare } & W4 & $\begin{array}{l}\text { Reduced working } \\
\text { hours }\end{array}$ & 0.812 & \multirow{5}{*}{3.188} & \multirow{5}{*}{0.842} \\
\hline & W2 & $\begin{array}{l}\text { Increased } \\
\text { remuneration }\end{array}$ & 0.809 & & \\
\hline & W7 & $\begin{array}{l}\text { Improved service } \\
\text { conditions }\end{array}$ & 0.781 & & \\
\hline & W5 & $\begin{array}{l}\text { Pleasant working } \\
\text { environment }\end{array}$ & 0.716 & & \\
\hline & W3 & Medical aid & 0.665 & & \\
\hline \multirow[t]{4}{*}{$\begin{array}{l}\text { Knowledge } \\
\text { and skills }\end{array}$} & KS2 & $\begin{array}{l}\text { Increased } \\
\text { employment } \\
\text { options }\end{array}$ & 0.8 .8 & \multirow{4}{*}{2.663} & \multirow{4}{*}{0.847} \\
\hline & KS4 & $\begin{array}{l}\text { Improved } \\
\text { operational } \\
\text { knowledge }\end{array}$ & 0.803 & & \\
\hline & KS5 & $\begin{array}{l}\text { Change in } \\
\text { perception }\end{array}$ & 0.740 & & \\
\hline & KS1 & $\begin{array}{l}\text { Driving skills } \\
\text { improvement }\end{array}$ & 0.661 & & \\
\hline
\end{tabular}

W, welfare; KS, knowledge and skills. 
TABLE 4: Results of factor analysis for former taxi operators

\begin{tabular}{|c|c|c|c|c|c|}
\hline Factor & Indicator & Indicator description & Loadings & Eigenvalues & Reliability \\
\hline \multirow{6}{*}{ Management } & M2 & Transparency and policy adherence & 0.843 & \multirow{6}{*}{3.918} & \multirow{6}{*}{0.882} \\
\hline & M3 & Transparency in appointing management & 0.811 & & \\
\hline & M1 & Participation adequacy & 0.770 & & \\
\hline & M7 & Management within expectations & 0.740 & & \\
\hline & M6 & Management capacitated & 0.726 & & \\
\hline & M4 & Professional appointment of board & 0.694 & & \\
\hline \multirow{5}{*}{ Service excellence } & SE3 & Reliable and efficient system & 0.883 & \multirow{5}{*}{3.831} & \multirow{5}{*}{0.848} \\
\hline & SE7 & Easily accessed by disabled & 0.881 & & \\
\hline & SE6 & Speed & 0.878 & & \\
\hline & SE4 & Convenience & 0.863 & & \\
\hline & SE9 & Increased number of passengers & 0.611 & & \\
\hline \multirow{4}{*}{ Environment } & E2 & Less pollution & 0.821 & \multirow{4}{*}{3.347} & \multirow{4}{*}{0.860} \\
\hline & E4 & Good vehicle engine & 0.818 & & \\
\hline & E3 & Pleasant environment & 0.814 & & \\
\hline & E1 & Reduced congestion & 0.665 & & \\
\hline \multirow{4}{*}{ Knowledge and skills } & KS2 & Knowledge transfer & 0.891 & \multirow{4}{*}{2.930} & \multirow{4}{*}{0.772} \\
\hline & KS1 & Improved operational skills & 0.872 & & \\
\hline & KS3 & Improved knowledge of operating taxis & 0.797 & & \\
\hline & KS4 & Positive business perception & 0.595 & & \\
\hline \multirow{3}{*}{ Welfare } & W1 & Reasonable financial compensation & 0.8666 & \multirow{3}{*}{2.324} & \multirow{3}{*}{0.737} \\
\hline & W2 & Fair fee per kilometre & 0.847 & & \\
\hline & W3 & Employees benefitted & 0.670 & & \\
\hline
\end{tabular}

$\mathrm{M}$, management; SE, service excellence; $\mathrm{E}$, environment; $\mathrm{KS}$, knowledge and skills; W, welfare.

vehicle to carbon emission standards and reduced congestion. Transfer of know-how, improved operational skills and a general positive business perception are indicators that explain the gain in knowledge and skills (factor 4). Finally, the welfare indicator is explained by a reasonable lump-sum compensation, reasonable fee per kilometre and benefits accorded to employees.

\section{Discussion}

Before drawing conclusions from this study, it is important to comment on some issues raised pertaining the background of this study. The discussion is therefore based on these pertinent issues that the authors consider important for the study.

The study was prompted by the reluctance of taxi operators to participate in the BRT transport initiative, arguing that their participation would make them worse off. Evidence from the study has shown that both the former taxi operators and drivers have greatly benefitted. These results are important in informing taxi operators on other routes that are earmarked for BRT. Furthermore, anticipated resistance will hopefully not be protracted as was the case in Phases 1A and 1B.

While the former taxi operators and drivers have benefitted from the negotiated contract that introduced BRT, it appears to have been at the expense of the city. The city facilitated the negotiations and was responsible for paying the lump-sum compensation. The city is also paying quarterly dividends and the fee per kilometre. The patronage that was forecasted has not been reached. Therefore, it is doubtful whether the revenue collected by the city is sufficient to cover these payments. In the qualitative interviews, concerns were raised by most city personnel on the compensation model that was viewed as a disadvantage for the city. One participant remarked, 'The compensation model needs to be reconfigured as its benefits were one-sided'.

A question that must be raised is why the city negotiated with taxi operators who had no experience of operating formal public transport, as opposed to affording other organisations or companies an opportunity to provide the service. The answer to this question is that the negotiated contract was a 'fait accompli' that emanated from political motivations. First, the policy allowed the awarding of a contract to those operators operating on the routes. Second, the empowerment factor compelled the city to negotiate with the taxi operators who fell under the marginalised category. Third, engaging any other service providers would have created a chaotic situation and most probably would have been vehemently resisted by taxi operators through violent means.

Taxi operators were enticed to venture into an unfamiliar business environment that was completely alien from the way they were used to conduct business. They were used to a modus operandi that allowed them to handle cash on a daily basis. The new operating system was different because revenue would only be realised after a period of time. For this reason, among others, negotiations were protracted and not easy.

There were some shortcomings on the nature and provisions of the contract. The contract provided for penalties in the event that the company fails to meet the 
requirements, which include missing trips and unclean buses inter alia, but in practice, this had hardly been implemented. A major weakness was the failure to provide productivity incentives, such as incentivising operators on the number of passengers carried, which would have helped to increase ridership.

The BRT project was introduced at the right time. Apart from the FIFA Soccer World Cup that the country was preparing to host, there was also a political angle that favoured its introduction. The BRT system was seen as a way of integrating the historically disadvantaged township of Soweto into the greater municipality of Johannesburg with a formal public transport system.

The BRT-negotiated contract has a life period of 12 years. The future of the contracts after the 12 years is not clear. Phase $1 \mathrm{~A}$ contract has 2 years to go, while phase $1 \mathrm{~B}$ contract is expiring in 2025. The city may not be in a position to continue paying the fee per kilometre. The options will be to renew the contract, or to open bus operations to other service providers. Therefore, the future sustainability of services needs to be carefully considered.

\section{Conclusion}

The negotiated contract that ushered in the BRT in Johannesburg took more than 3 years to be finalised. The experience has demonstrated that dealing with informal taxi operators is a complex issue. Equally, the taxi operators cannot be side-lined because any move to introduce a competing mode on routes they operate will be resisted.

Loss of revenue was the main reason that taxi operators were not keen to participate in the BRT project. Notwithstanding their reservations, it turned out that their participation was beneficial. Both former minibus taxi operators and drivers had gained knowledge and skills in the new formal public transport system. The training that was accorded to both drivers and former operators has greatly assisted in changing the mind-set. Drivers were the main beneficiaries whose welfare greatly improved from a mere wage, principally based on commission, to a monthly salary coupled with other benefits. Overall, there was an improvement on former taxi operators' welfare as some were able to make meaningful investments to generate more income. However, these benefits are at the expense of the city and future sustainability may be questionable.

Bus rapid transit was providing a quality service as adjudged by stakeholders. With greater enforcement not to allow the general traffic to use bus lanes, upscaling BRT to other corridors and a meaningful reduction of taxis, BRT has the potential to improve the urban environment. The BRT had positively impacted on employment and good governance through the empowerment of previously marginalised taxi operators.
The non-participation of Phase 1A shareholders and drivers has been a major limitation to this study. Ideally, a comparison of the two phases (Phase 1A and 1B) would have provided added value to this study because the two models were crafted differently. This is an area that future research needs to consider investigating. Secondly, the study focused solely on the benefits to the key stakeholders of the negotiated contract without addressing the costs that have contributed to those benefits. Future research needs to undertake a comprehensive study that addresses both costs and benefits in to determine whether these benefits are not at the expense of excessive costs.

\section{Acknowledgements Competing interests}

The authors have declared that no competing interests exist.

\section{Authors' contributions}

B.M. was responsible for data collection, while T.M. analysed the data and wrote the article.

\section{Ethical consideration}

The study received ethical clearance from the University of Johannesburg's CBE Research Ethics Committee. Reference number: CBEREC19JBS01.

\section{Funding information}

This research received no specific grant from any funding agency in the public, commercial or not-for-profit sectors.

\section{Data availability statement}

Data collected will be stored for 5 years and can be requested from the corresponding author.

\section{Disclaimer}

The views and opinions expressed in this article are those of the authors and do not necessarily reflect the official policy or position of any affiliated agency of the authors.

\section{References}

Allen, H., 2013, Africa's first full rapid bus system: The Rea Vaya bus system in Johannesburg, South Africa, Case study prepared for global report on human settlements (2013), viewed 15 July 2019, from http://www.unhabitat.org/grhs/2013.

Armstrong-Wright, A., 2000, 'Bus services: Deregulation and privatisation', Indian Journal of Transport Management June, 421-436.

Batoev, G. \& Schlosser, C., 2013, The advantages and disadvantages of the various procurement procedures, Student paper, Coordinators: Schoenmaekers, S. \& Philipsen, N., viewed on 15 July 2019, from https://www.maastrichtuniversity. $\mathrm{nl} /$ sites/default/files/2013/batoev.pdf.

Davis, M.J., 2014, 'Procurement practices influencing service delivery: A case of Kenya power', European Journal of Logistics Purchasing and Supply Chain Management 2(3), 79-137.

Demel, S.M., Woodall, B., Anderson, E., Walton, J.M. \& Mass, B., 2013, Negotiation: Lost art or core competency? The Institute for Public Procurement, viewed on 03 February 2020, from https://www.nigp.org/docs/default-source/New-Site/ position-papers/150105_negotiation_position-paper_complete_updated. pdf?sfursn=. 
Filippini, M., Koller, M. \& Masiero, G., 2015, 'Competitive tendering versus performancebased negotiation in Swiss public transport', Transportation Research Part A: Policy and Practice 82, 158-168. https://doi.org/10.1016/j.tra.2015.09.007

Flores, O. \& Diaz, R., 2019, 'Transportation governance in Latin America: BRT as a tool for structural change or as a tweak over existing conditions', VREF Research Synthesis Project Governance of Metropolitan Trasport Background Paper, Synthesis Projer, viewed 25 February 2020, from http://www.vref.se/download/18.45182a5f16a84 e95fac6750 / 15602364020 overnance $\% 20$ in 20 change $\% 20 \% 20$ or\%20as\%20a\%20tweak\%200ver\%20existing\%20conditions.pdf.

Global Labour Institute (GLI), 2019, Nairobi bus transit system: Labour impact assessment report, January 2019, viewed on 06 September 2019, from https:// issuu.com/itf_rpc/docs/brt_labour_impact_assessment_report_2019.

Hensher, D. \& Stanley, J., 2003, 'Performed based contracts in public transportation: The Melbourne experience', in 8th International Conference Proceedings on Competition and Ownership in Land Passenger Transport (Thredbo 8) Held in Rio de Janeiro, Brazil, and Ownership in Land Passength

Hidson, M. \& Müller, M., 2003, Better public transport for Europe through competitive tendering: A good practice guide, ICLEI - Local Governments for Sustainability, viewed on 12 September 2019, from https://www.bkb.admin.ch/dam/bkb/fr/ dokumente/Oeffentliches_Besch.

Hidalgo, D Graftieaux, P., 2008, 'Bus rapid transit systems in Latin America and Asia: Results and difficulties in 11 cities', Transportation Research Record: Journal of the Transportation Research Board 2072(1), 77-88. https://doi.org/10.3141/ 2072-09

Institute for Transportation and Development Policy (ITDP) n.d., BRT Planning Guide, vol. 4, Business Plan, viewed 5 February 2020, from https://brtguide.itdp.org/ branch/master/guide/business-structure/brt-operating-contract-types

Kavanagh, P., 2016, 'A case for negotiated performance-based contracting rather than competitive tendering in government public transport (bus) service procurement. Elsevier', Research in Transport Economics 59, 313-322.

Klopp, J.M., Harber, J. \& Quarshie, M., 2019, 'A review of BRT as public transport reform in African cities', VREF Research Synthesis Project Governance of Metropolitan Transport Background Paper, viewed 25 February 2020, from https://www.researchgate.net/publication/333971452A_REVIEW_OF_BRT_AS PUBLIC_TRANSPORT_REFORM_IN_AFRICAN_CITIES.

Kulyk, W. \& Hardy, M., 2003, ITS enhanced bus rapid transit systems, Director Office of Mobility Innovation, U.S. Department of Transportation Federal Transit Administration, Washington (202):366-4991, viewed on 20 October 2019, from http://onlinepubs.trb.org/onlinepubs/archive/conferences/vha-brt/its enhanced bus rapid_transit_systems.pdf.

Maunganidze, L., 2011, 'The role of bus rapid transit in improving public transport levels of service, particularly for the urban poor users of public transport: A case of Cape Town, South Africa', Masters' dissertation, University of Cape Town, Rondebosch, Cape Town.
Mbara, T., Dumba, S. \& Mukwashi, T., 2014, 'Multi-stakeholder dialogue on formal and informal forms of public transport in Harare, Zimbabwe: Convergence or divergence perspective', Journal of Transport and Supply Chain Management 8(1) a140. https://doi.org/10.4102/jtscm.v8i1.140

National Land Transport Act, No 5 of 2009, 2009, Government Gazette. (No. 32110).

National Land Transport Act, 2009, (Government Gazette no. 32110), viewed on 20 October 2019, from http://www.saflii.org/za/legis/num_act/nlta2009258.pdf.

Oviedo, P.D., Scholl, L., Innao, M. \& Pedraza, L., 2019, 'Do bus rapid transit systems improve accessibility to job opportunities for the poor? The case of Lima, Peru', Sustainability 11(10), 2795. https://doi.org/10.3390/su11102795

Seftel, L., 2013, 'Pains and gains of a negotiated contract: The Johannesburg Rea Vaya BRT experience, Transport Department, City of Johannesburg, South Africa', Paper presented at the 13th International Conference on Competition and Ownership in Land Passenger Transport St Anne's College, University of Oxford, United Kingdom, 15-19th September 2013.

Sohail, M., Mitlin, D. \& Maunder, D.A.C., 2003, Guidelines: Partnership to improve access and quality of public transport, WEDC, Loughborough University, Loughborough.

The World Bank Group \& PPIAF, 2006, Urban Bus Toolkit, Tools and options for reforming urban bus systems, viewed on 20 February 2020, from https://ppiaf.org/sites/ppiaf. org/files/documents/toolkits/UrbanBusToolkit/assets/3/3.5/35(i).html.

Van de Velde, D., 2003, Regulation and competition in the European land transport industry: Some recent evolutions, Working paper at the 8th Conference on Competition and Ownership in Land Passenger Transport, 14th-18th Septembe 2003 Conference location: Rio De Janeiro, Brazil.

Venter, C., 2016, 'Assessing the potential of bus rapid transit-led network restructuring for enhancing affordable access to employment: The case of Johannesburg's corridors of freedom', Research in Transport Economics 59 441-449, viewed from https://www.sciencedirect.com/science/article/abs/pii/ S0739885915300743.

Verachtert, E., Kasaija, P., Loopmans, M. \& Van Rompae, A., 2015, 'Who could benefit from a bus rapid transit system in cities from the developing countries? A case study from Kampala, Uganda', Journal of Transport Geography 47(2015), 13-22. https://doi.org/10.1016/j.jtrangeo.2015.07.006

Walters, J. \& Cloete, D., 2008, 'The South African experience with negotiated versus competitively tendered bus contracts', Transport Research Part A 42(9), 1163-1175. https://doi.org/10.1016/j.tra.2008.05.002

Windecker, A., 2002, 'Defining the gross cost and net cost options for New Delhi Public Transport', Journal of Public Transportation 5(1), 87-104.

Wilson, J., 2014, Essentials of business research. A guide to doing your research project, 2nd edn., J. Seaman (ed.), Sage, Cambridgeshire.

World Bank, 2018, Procurement guidance, negotiations and best and final offer (BAFO) use of negotiations and BAFO in procurement of goods, works, and nonconsulting services, viewed on 15 August 2019, from http://pubdocs.worldbank. org/en/663621519334519385/Procurement-GuidanceNegotiation-and-BestFinal-Offer.pdf. 